\title{
Analisis Rugi Energi Pada Jaringan Tegangan Rendah Sehubungan Dengan Penggantian Jenis Connector
}

\author{
I Gede Budhi Arsana*, Wayan Gede Ariastina, I Nyoman Setiawan \\ Jurusan Teknik Elektro Fakultas Teknik Universitas Udayana \\ *Email: gd.budhiarsana@yahoo.com
}

\begin{abstract}
Abstrak
Rugi energi terjadi jika jumlah energi yang disalurkan tidak sama dengan energi yang diterima oleh konsumen tenaga listrik. Rugi energi merupakan salah satu parameter kualitas jaringan listrik. Rugi energi yang tinggi pada jaringan dapat mengakibatkan pula rugi tegangan yang tinggi, sehingga tegangan pelayanan menjadi turun. Menurut SPLN 1, 1995 tegangan pelayanan maksimum adalah $+5 \%$ dan minimun $-10 \%$ terhadap tegangan nominal. Salah satu cara untuk menurunkan rugi energi yang dilaksanakan oleh PT PLN (Persero) adalah dengan mengganti tap connector tiap sambungan jaringan tegangan rendah dengan connector type press. Penelitian ini menganalisis besarnya rugi energi yang terjadi sebelum penggantian dan setelah penggantian connector. Hasil analisis menunjukkan bahwa dengan dilaksanakannya penggantian tap connector, maka rugi energi pada jaringan tegangan rendah yang terhubung pada transformator DS105 dapat diturunkan sebesar 63,4327 Wh atau sebesar 23,2448\%. Dengan kata lain, rugi energi dapat diturunkan dari 272,8896 Wh sebelum penggatian tap connector menjadi 209,4569 Wh setelah penggantian tap connector.
\end{abstract}

Kata Kunci - Jaringan tegangan rendah, rugi energi, tap connector, connector press.

\begin{abstract}
Energy loss occurs if the amount of energy supplied is not the same as that received by consumers of electric power. Loss of energy is one of the quality parameters of the electricity network. High energy loss on the network can also result in high loss of voltage, making the service voltage declining. According to the SPLN 1, 1995 the maximum service voltage is + 5\% and $-10 \%$ minimum of the nominal voltage. One way to reduce the energy loss that carried out by PT PLN (Limited) is to replace the tap connector of each low voltage network connection with connector type press. This study analyzes the amount of energy loss that occurs before and after the replacement of connector. The results showed that with the implementation of the replacement of tap connector, the energy loss in the low voltage network which is connected to the transformer of DS105 could be reduced by 63.4327 Wh or equivalent to $23.2448 \%$. In other words, the energy loss can be reduced from the 27.8896 Wh before replacement of tap connector become $209.4569 \mathrm{Wh}$ after the replacement of tap connector.
\end{abstract}

Keywords: Low voltage networks, loss of energy, tap connector, connector press.

\section{PENDAHULUAN}

Seiring dengan kewajiban PLN untuk menyediakan listrik yang berkualitas bagi pelanggan maka diperlukan standar pelayanan yang baik. Hal ini bisa terwujud apabila proses perencanaan, pelaksanaan pembangunan, pengoperasian dan pemeliharaan suatu sistem tenaga listrik senantiasa mengikuti ketentuan standar teknik yang berlaku. Pendistribusian energi listrik dari pembangkit sampai ke konsumen sering terjadi hilangnya energi atau susut energi.

Rugi energi adalah suatu kondisi atau keadaan dimana jumlah energi yang disa- lurkan tidak sama dengan energi yang diterima. Terjadinya rugi-rugi energi ini dapat disebabkan oleh berbagai faktor seperti jauhnya daerah penyaluran tenaga listrik dari sumber, ketidakseimbangan beban, luas penampang penghantar, umur peralatan, sambungan antar penghantar yang tidak sempurna dan lain-lain.

Susut energi distribusi nasional untuk tahun 2013 ditetapkan menjadi 8.5\% sesuai dengan keputusan Direktur Jenderal Ketenagalistrikan Kementerian Energi dan Sumber Daya Mineral [1]. Sehubungan dengan hal tersebut, PT PLN (Persero) Dis- 
tribusi Bali Area Bali Selatan berusaha untuk menekan rugi teknis maupun rugi nonteknis yang terjadi pada jaringan, sehingga tegangan pelayanan dapat terjaga sesuai dengan standar yang telah ditetapkan. Berdasarkan Standar PLN No. 1 Tahun 1995, tegangan pelayanan maksimum adalah $+5 \%$ dan minimun $-10 \%$ terhadap tegangan nominal [2].

Hasil survei awal pada jaringan tegangan rendah (JTR) yang terhubung dengan gardu distribusi DS. 105, diketahui adanya indikasi terjadinya rugi-rugi energi yang cukup signifikan. Salah satu penyebab tingginya rugi-rugi energi tersebut adalah telah menuanya connector pada percabangan jaringan tegangan rendah.

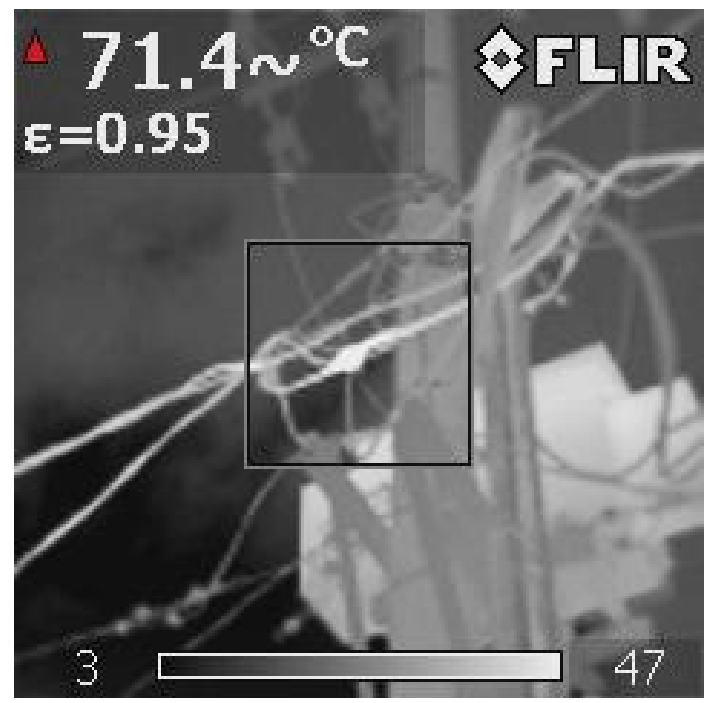

Gambar 1. Pengukuran suhu connector dengan menggunakan thermovision

Hasil pengukuran suhu connector dengan menggunakan thermovision menunjukkan adanya kenaikan suhu pada connector penghubung SR dan JTR, serta pada sambungan JTR. Suhu yang terukur pada connector yang rusak di JTR mencapai $44,4^{\circ} \mathrm{C}$, sedangkan pada sambungan kabel JTR suhunya bisa mencapai $71,4^{\circ} \mathrm{C}$. Kenaikan suhu pada connector menyebabkan kenaikan resistansi atau hambatan pada connector sehingga akan timbul rugi rugi energi berupa energi panas. Gambar 1 menunjukkan pengukuran suhu pada connector sebelum dilakukan penggantian. Untuk mengurangi rugi energi yang terjadi, maka perlu dilakukan penggantian connector yang sudah tua dan rusak dengan menggunakan connector baru.
Penelitian ini difokuskan pada analisis besarnya rugi energi yang terjadi sebelum penggantian dan setelah penggantian connector. Analisis rugi energi dilakukan pada jaringan tegangan rendah yang terhubung pada transformator DS105. Connector yang digunakan sebelumnya adalah dari jenis tap connector, sedangkan connector pengganti yang digunakan adalah dari jenis connector type press, seperti ditunjukkan pada Gambar 2 dan 3 [3].
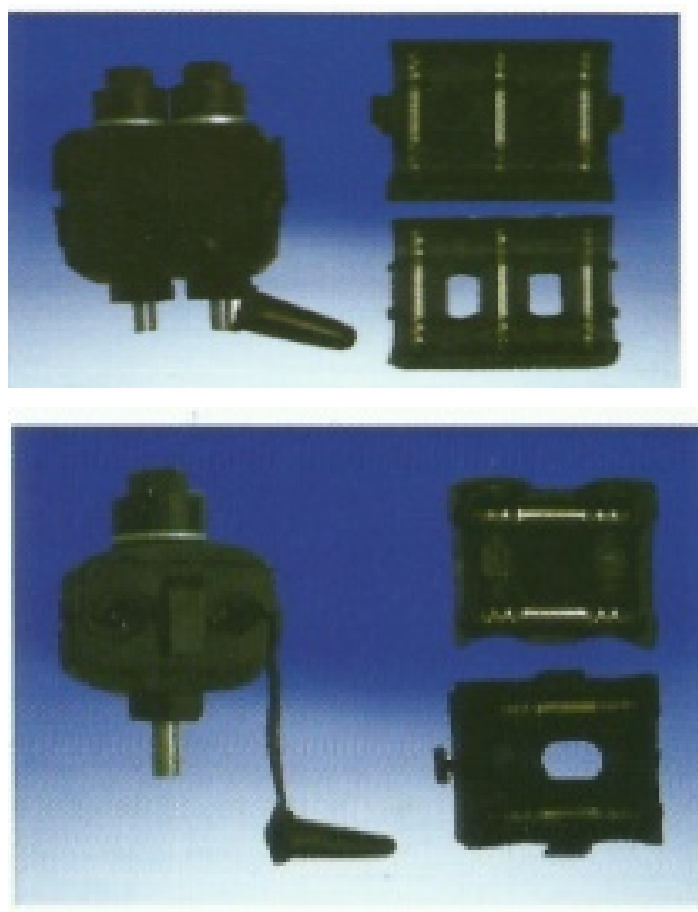

Gambar 2. Tap connector
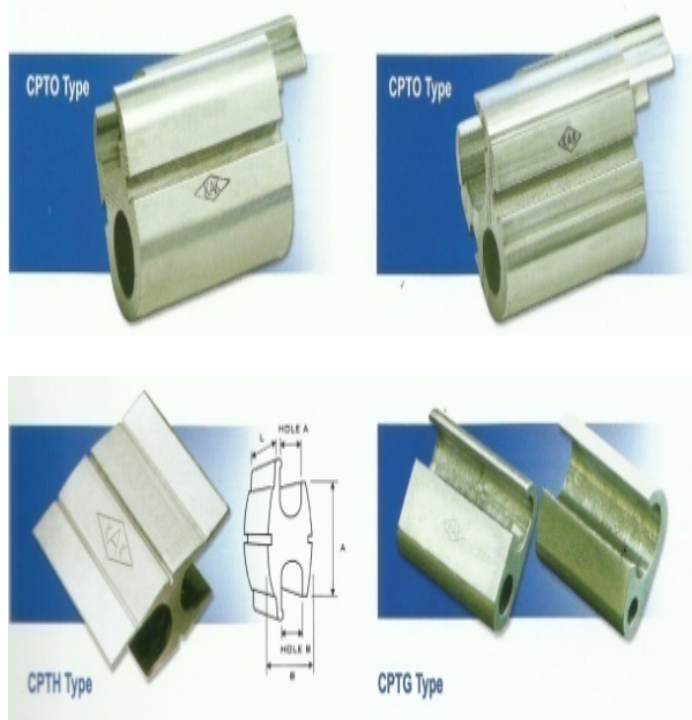

Gambar 3. Connector type press 


\section{RUGI ENERGI}

\subsection{Rugi Pada Sambungan Tidak Sem- purna}

Rugi energi dapat terjadi pada titik-titik sambungan sepanjang jaringan tegangan rendah, antara lain :

1. Sambungan antara kabel opstyg dengan kabel Low Voltage Twist Cable 3x70+ $1 \times 50 \mathrm{~mm}^{2}$ seperti ditampilkan pada Gambar 4.

2. Sambungan antar saluran jaringan tegangan rendah atau antar kabel Twist Insulated Cable 2x10 $\mathrm{mm}^{2}$.

3. Percabangan saluran jaringan tegangan renda, seperti pada Gambar 5.

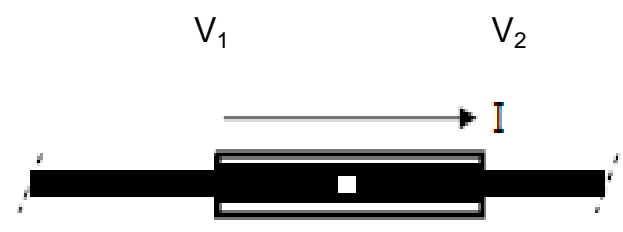

$\mathrm{R}$

Gambar 4. Sambungan kabel

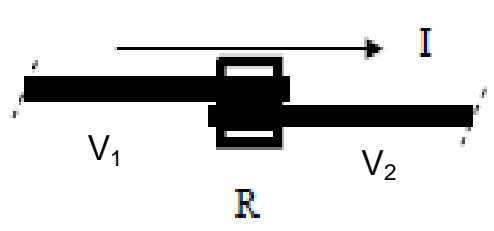

Gambar 5. Percabangan kabel

\subsection{Perhitungan Rugi Energi}

Besarnya resistansi pada sambungan dan percabangan connector dapat dihitung dengan menggunakan Persamaan (1) berikut ini:

$$
R=\frac{V_{1}-V_{2}}{I}
$$

Keterangan :

$\begin{array}{ll}R & \text { adalah resistansi connector } \\ V_{1} & \begin{array}{l}\text { adalah tegangan sebelum } \\ \text { titik sambung }\end{array} \\ V_{2} & \begin{array}{l}\text { adalah tegangan sesudah } \\ \text { titik sambung }\end{array} \\ I & \begin{array}{l}\text { adalah arus yang mengalir } \\ \text { pada connector }\end{array}\end{array}$

Besarnya rugi-rugi daya yang timbul pada sambungan dirumuskan seperti pada Persamaan (2):

$$
P_{\text {losses }}=(I)^{2} \cdot R
$$

Keterangan :

$$
\begin{array}{ll}
P_{\text {losses }} & \text { adalah rugi daya nyata } \\
I & \text { adalah arus yang mengalir } \\
R & \text { adalah resistansi connector }
\end{array}
$$

Energi yang hilang akibat terjadinya susut daya ini dapat dihitung dengan Persamaan (3) sebagai berikut:

$$
W_{\text {losses }}=P_{\text {losses }} \times t
$$

Keterangan :

$$
\begin{array}{ll}
W_{\text {losses }} & \multicolumn{1}{c}{\text { adalah rugi energi }} \\
P_{\text {losses }} & \text { adalah rugi daya } \\
t & \text { adalah waktu }
\end{array}
$$

\section{METODE PENELITIAN}

Penelitian dilaksanakan pada jaringan tegangan rendah yang terhubung dengan gardu DS 105. Pengukuran tegangan dan arus dilakukan pada 47 buah connector. Pengukuran tegangan dan arus pada connector dilakukan dua kali, yaitu sebelum penggantian tap connector dan pengukuran kedua setelah dilaksanakannya pengantian. Gambar 6 dan 7 masing-masing menunjukkan kegiatan pengukuran tegangan dan arus di gardu tiang dan di titik penyambungan kabel. Gambar 8 menunjukkan kegiatan penggantian connector yang rusak.

Data hasil pengukuran pada masingmasing connector selanjutnya digunakan untuk menghitung resistansi akibat buruknya kontak pada connector, rugi daya yang ditimbulkan dan rugi energi rata-rata yang terjadi selama satu hari (24 jam).

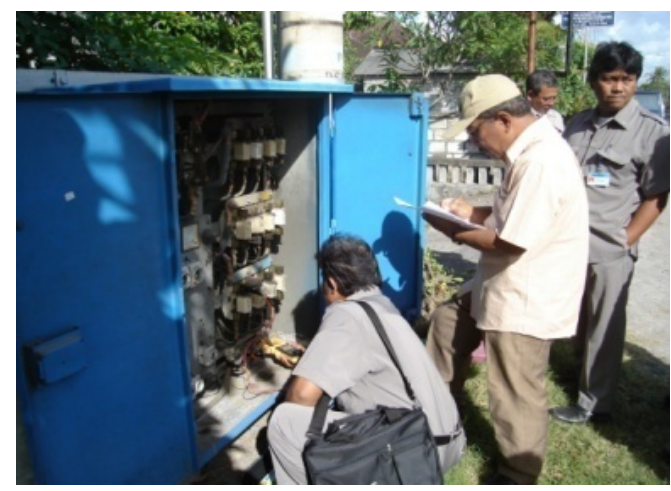

Gambar 6. Pengukuran di gardu 


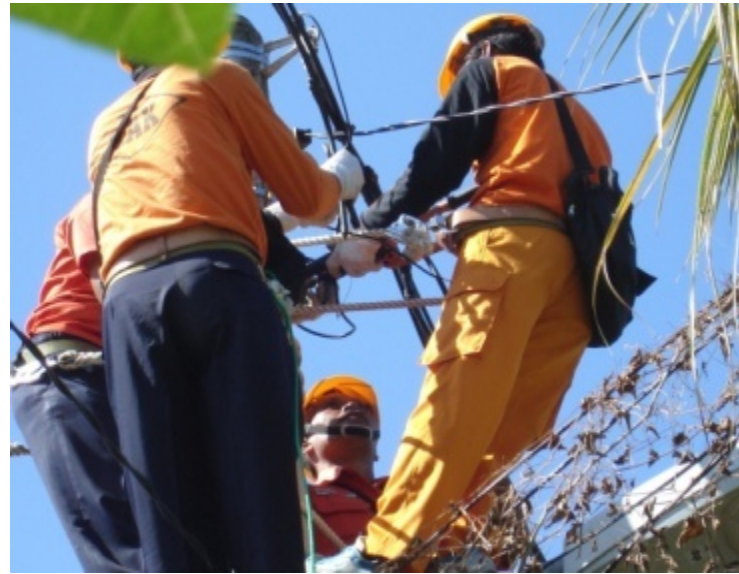

Gambar 7. Pengukuran di JTR

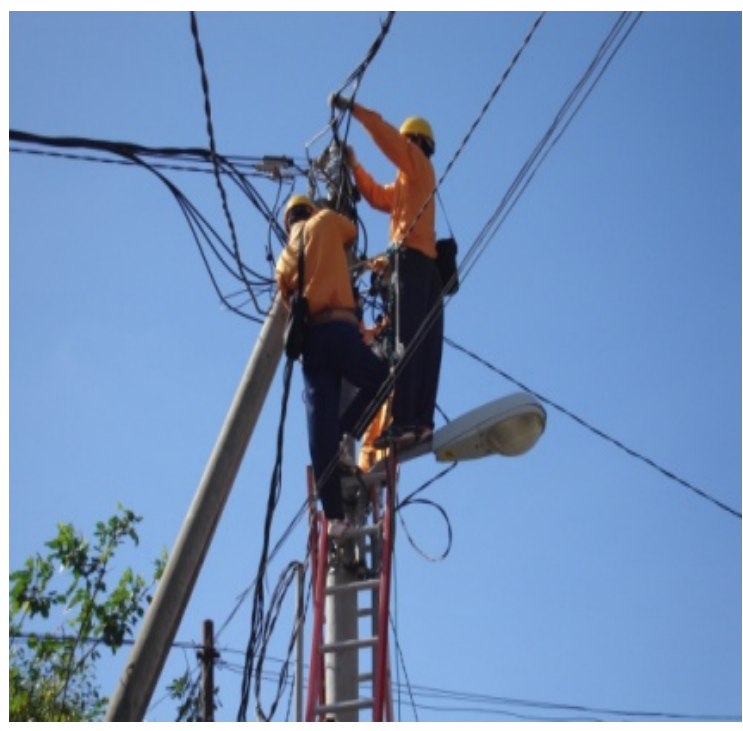

Gambar 8. Penggantian tap connector

\section{HASIL DAN PEMBAHASAN}

\subsection{Hasil Pengukuran Tegangan dan Arus}

Pengukuran tegangan di kedua ujung sambungan dilakukan pada titik V1 dan V2 seperti ditampilkan pada Gambar 4 dan 5 . Sedangkan pengukuran arus dilakukan di salah satu ujung sambungan. Hasil pengukuran tegangan dan arus sebelum dan setelah dilakukannya penggantian jenis connector dapat dilihat pada Tabel 1.
Tabel 1. Hasil pengukuran tegangan dan arus

\begin{tabular}{|c|c|c|c|c|c|c|c|}
\hline \multirow{3}{*}{ №. } & \multirow{3}{*}{ №. Tiang } & \multicolumn{3}{|c|}{ Sebelum Penggantian } & \multicolumn{3}{|c|}{ Sesudah Penggantian } \\
\hline & & \multicolumn{2}{|c|}{ Tegangan (Volt) } & \multirow{2}{*}{$\begin{array}{l}\text { Arus } \\
\text { (A) }\end{array}$} & \multicolumn{2}{|c|}{ Tegangan (Volt) } & \multirow{2}{*}{$\begin{array}{l}\text { Arus } \\
\text { (A) }\end{array}$} \\
\hline & & VI & V2 & & $\mathrm{VI}$ & V2 & \\
\hline 1 & B2AI & 215.192 & 215.180 & $\begin{array}{l}.000 \\
\end{array}$ & 227.382 & 227.372 & 4.100 \\
\hline 2 & B2Al & 206.789 & 206.779 & 5.000 & 222.568 & 222.556 & 5.000 \\
\hline 3 & B2Al & 222.192 & 222.186 & 1.700 & 229.114 & 229.109 & 1.800 \\
\hline 4 & B2A2 & 212.244 & 212.236 & 2.000 & 226.878 & 226.872 & 1.600 \\
\hline 5 & B2A2 & 204.784 & 204.781 & 1.000 & 221.012 & 221.009 & 1.000 \\
\hline 6 & B2A2 & 221.882 & 221.879 & 0.600 & 227.018 & 227.015 & 0.600 \\
\hline 7 & B2A4 & 207.695 & 207.685 & 4.100 & 224.120 & 224.|II & 3.700 \\
\hline 8 & B2A4 & 199.244 & 199.218 & 6.700 & 219.157 & 219.140 & 8.000 \\
\hline 9 & B2A4 & 219.136 & 219.120 & 6.500 & 225.585 & 225.571 & 6.300 \\
\hline 10 & B2 А5BI & 201.237 & 201.224 & 3.000 & 220.198 & 220.186 & 3.000 \\
\hline$\|$ & B2A5BI & 194.478 & 194.465 & 5.100 & 210.098 & 210.086 & 5.000 \\
\hline 12 & $\mathrm{~B} 2 \mathrm{~A} \mathrm{BB}$ & 211.582 & 211.562 & 1.000 & 222.286 & 222.282 & 2.200 \\
\hline 13 & B2А5В2 & 199.685 & 199.671 & 6.000 & 218.986 & 218.973 & 6.200 \\
\hline 14 & B2А5B2 & 192.285 & 192.250 & 16.200 & 207.597 & 207.565 & 15.800 \\
\hline 15 & B2 А5B2 & 210.982 & 210.972 & 4.200 & 220.095 & 220.086 & 4.100 \\
\hline 伍 & B2A5B3 & 215.375 & 215.350 & 11.500 & 215.030 & 215.007 & 11.200 \\
\hline 17 & B2 АБВЗ & 202.753 & 202.740 & 4.800 & 202.597 & 202.587 & 4.200 \\
\hline 18 & B2А5В3 & 215.686 & 215.671 & 6.100 & 215.198 & 215.184 & 6.0०० \\
\hline 19 & B2A5B 4 & 213.249 & 213.236 & 4.000 & 213.089 & 213.077 & 4.0०0 \\
\hline 20 & B2A5B 4 & 199.554 & 199.532 & 7.500 & 202.487 & 202.471 & 7.200 \\
\hline 21 & B2A5B 4 & 214.566 & 214.559 & 2.100 & 213.197 & 213.191 & 1.900 \\
\hline 22 & B2 АБB5 & 194.488 & 194.471 & 7.800 & 211.796 & 211.781 & 7.400 \\
\hline 23 & B2 АБB5 & 187.258 & 187.229 & 13.100 & 197.213 & 197.185 & 12.800 \\
\hline 24 & B2A5B5 & 205.142 & 205.122 & 9.200 & 212.148 & 212.129 & 9.100 \\
\hline 25 & B2A5B5AI & 192.719 & 192.700 & 4.200 & 208.217 & 208.200 & 4.100 \\
\hline 26 & B2 А5B5AI & 186.892 & 186.873 & 7.200 & 193.434 & 193.47 & 7.100 \\
\hline 27 & В2 А5В5АI & 204.674 & 204.660 & 6.100 & 210.119 & 210.106 & 5.900 \\
\hline 28 & В2АБВБА2 & 192.698 & 192.678 & 8.200 & 206.172 & 206.153 & 7.900 \\
\hline 29 & В2АБВБА2 & 184.778 & 184.738 & 19.500 & 192.758 & 192.720 & 19.000 \\
\hline 29 & B2 АБВ5А2 & 184.778 & 184.738 & 19.500 & 192.758 & 192.720 & 19.000 \\
\hline 30 & В2АБВБА2 & 203.783 & 203.767 & 6.100 & 210.539 & 210.523 & 6.200 \\
\hline 31 & В2 АБВБАЗ & 205.152 & 205.131 & 8.100 & 205.228 & 205.210 & 8.000 \\
\hline 32 & В2АБВБАЗ & 187.445 & 187.398 & 12.100 & 187.398 & 187.370 & 11.800 \\
\hline 33 & B2АБB5АЗ & 209.655 & 209.630 & 11.700 & 209.368 & 209.344 & 11.500 \\
\hline 34 & В2АБВ5АЗЗВ & 188.678 & 180.629 & 9.700 & 201.179 & 201.152 & 9.400 \\
\hline 35 & B2 AБB5АЗBI & 181.262 & 181.237 & 11.200 & 184.139 & 184.110 & 10.800 \\
\hline 36 & B2 ASB5A3BI & 201.578 & 201.561 & 6.600 & 207.648 & 207.633 & 6.100 \\
\hline 37 & В2АБВ5АЗВ2 & 187.134 & 187.117 & 7.100 & 199.198 & 199.182 & 7.000 \\
\hline 38 & В2 АБB5АЗВВ2 & 180.875 & 180.850 & 10.300 & 183.178 & 183.156 & ।0.००र \\
\hline 39 & В2 АБВ5АЗВЗ & 185.789 & 185.750 & 18.000 & 198.266 & 198.229 & 17.800 \\
\hline 40 & B2 АБВ5АЗВЗ & 178.893 & 178.838 & 18.300 & 183.578 & 183.528 & 17.600 \\
\hline 41 & В2АБВ5АЗВЗ & 199.221 & 199.119 & 20.500 & 206.229 & 206.187 & 20.००० \\
\hline 42 & B2A5B5A3B 4 & 183.278 & 183.252 & 11.200 & 198.125 & 198.100 & 10.800 \\
\hline 43 & В2АБВ5АЗВ 4 & 177.959 & 177.930 & 10.700 & 184.349 & 184.325 & 10.100 \\
\hline 44 & B2 АБВ5АЗВ 4 & 198.559 & 198.540 & 6.400 & 206.136 & 206.123 & 6.000 \\
\hline 45 & В2АБВ5АЗЗВ5 & 184.672 & 184.646 & 12.100 & 197.126 & 197.101 & 11.700 \\
\hline 46 & В2АБВ5АЗВ5 & 176.253 & 176.232 & 8.700 & 180.187 & 180.168 & 8.100 \\
\hline 47 & В2 АБВ5АЗВБ & 197.844 & 197.830 & 6.700 & 204.275 & 204.263 & 6.200 \\
\hline
\end{tabular}

\subsection{Hasil Perhitungan Rugi Daya dan Rugi Energi}

Hasil perhitungan rugi daya dan rugi energi sebelum penggantian dan sesudah penggantian jenis connector dapat dilihat pada Tabel 2. Berdasarkan hasil perhitungan rugi energi sebelum dan sesudah penggantian jenis connector, dapat dilihat adanya penurunan rugi energi di tiap-tiap titik sambung connector. Sebagai contoh pada tiang B2A1 rugi energi sebelum penggantian connector adalah $1,1520 \mathrm{Wh}$ dan sesudah penggantian connector menjadi 0,9840 Wh. Dengan demikian terdapat penurunan rugi energi sebesar $0,168 \mathrm{Wh}$ atau sekitar $14,58 \%$. 
Tabel 2. Hasil perhitungan rugi daya dan rugi energi

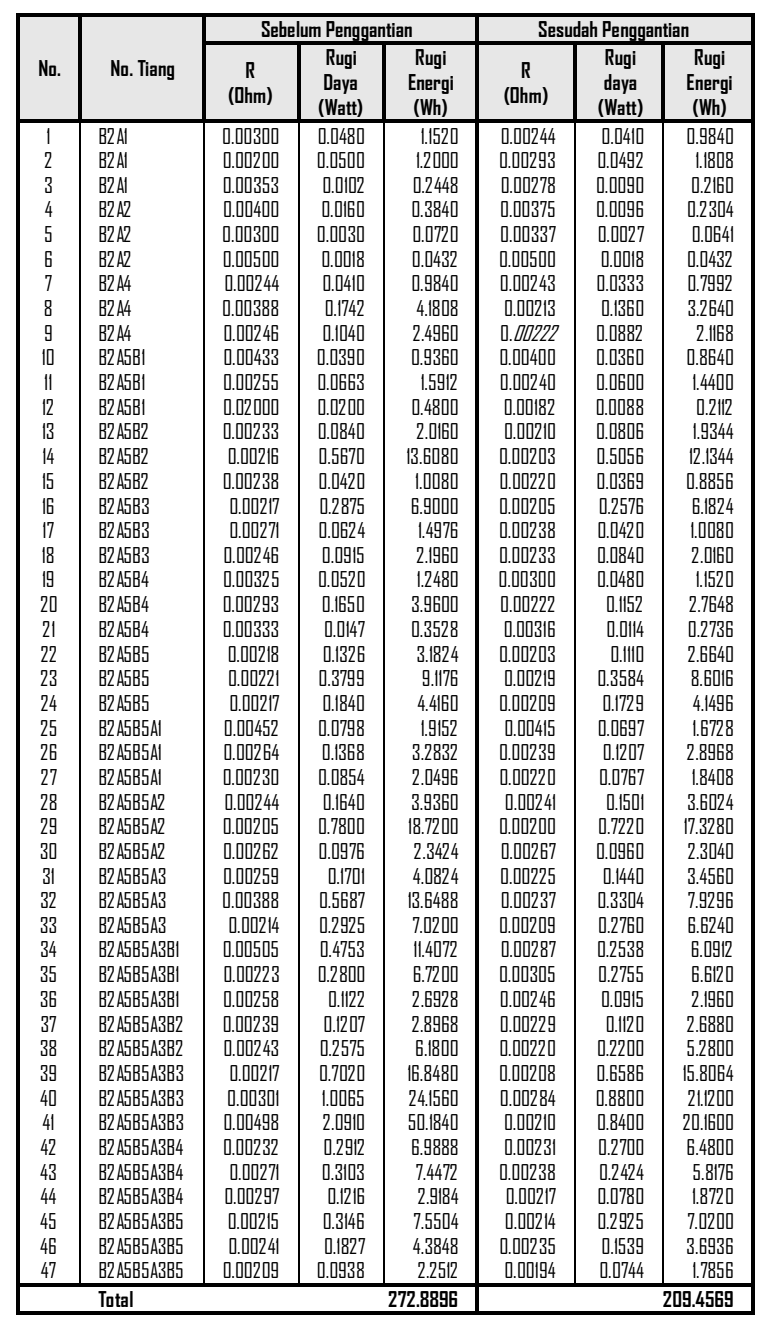

Nilai resistansi pada connector type press yang masih cukup tinggi setelah penggantian dapat disebabkan oleh kesalahan dalam prosedur pemasangan seperti pada Tabel 2 dapat dilihat bahwa. Kesalahan prosedur saat pemasangan connector dapat menyebabkan timbulnya rongga yang mengakibatkan buruknya kontak penghantar dengan connector, sehingga menimbulkan kenaikan suhu pada connector sebagai akibat dari tingginya resistansi pada connector.

Secara umum pada setiap titik sambung connector terjadi penurunan rugi daya dan rugi energi seperti dapat dilihat pada Tabel 3. Dengan demikian, secara keseluruhan, penurunan rugi energi setelah penggantian connector adalah sebesar:

$$
\begin{aligned}
\Delta W & =W_{\text {losses sebelum }}-W_{\text {losses sesudah }} \\
& =272.8896-209.4569 \\
& =63.4327 \mathrm{Wh}
\end{aligned}
$$

\begin{tabular}{|c|c|c|c|c|}
\hline №. & No. Tiang & $\begin{array}{c}\Delta \mathrm{PP} \\
\text { (watt) }\end{array}$ & $\begin{array}{c}\Delta W \\
\text { (watt hour) } \\
\end{array}$ & $\begin{array}{c}\text { Persen-tase } \\
\text { (\%) }\end{array}$ \\
\hline$T$ & B2AI & 0.0070 & 0.1680 & 14.5833 \\
\hline 2 & B2Al & 0.0008 & 0.0192 & 1.6000 \\
\hline 3 & B2Al & 0.012 & 0.0288 & 11.7647 \\
\hline 4 & B2A2 & 0.0064 & 0.1536 & 40.0 \\
\hline 5 & B2A2 & 0.0003 & 0.0079 & 11.0 \\
\hline 6 & B2A2 & 0 & 0 & [ \\
\hline 7 & B2A4 & 0.0077 & 0.1848 & 18.7805 \\
\hline 8 & B2A4 & 0.0382 & 0.9168 & 21.9288 \\
\hline 9 & B2A4 & 0.0158 & 0.3792 & 15.1923 \\
\hline 10 & B2 А5BI & 0.0030 & 0.0720 & 7.6923 \\
\hline$\|$ & B2A5BI & 0.0063 & 0.1512 & 9.5023 \\
\hline 12 & B2 A5BI & 0.0 메2 & 0.2680 & 56.0 \\
\hline 13 & B2АБB2 & 0.0034 & 0.0816 & 4.0476 \\
\hline 14 & B2A5B2 & 0.0614 & 1.4736 & 10.8289 \\
\hline 15 & B2 АБB B & 0.0051 & 0.1224 & 12.1429 \\
\hline 伍 & B2АБВЗ & 0.0299 & 0.7176 & 10.4 \\
\hline 17 & B2А5ВЗ & 0.0204 & 0.4896 & 32.6923 \\
\hline 18 & B2АБВЗ & 0.0075 & 0.1800 & 8.1967 \\
\hline 19 & B2A5B 4 & 0.0040 & 0.0960 & 7.6923 \\
\hline 20 & B2 $\mathrm{A} 5 \mathrm{~B} 4$ & 0.0498 & 1.1952 & 30.1818 \\
\hline 21 & B2A5B 4 & 0.0033 & 0.0792 & 22.4490 \\
\hline 22 & B2АГВБ5 & 0.0216 & 0.5184 & 16.2896 \\
\hline 23 & B2 АБB B5 & 0.0215 & 0.5160 & 5.6594 \\
\hline 24 & В2 А5В5 & 0.0IIII & 0.2664 & 6.0326 \\
\hline 25 & В2 А5ВБАI & 0.0101 & 0.2424 & 12.6566 \\
\hline 26 & B2 А5B5AI & 0.0161 & 0.3884 & 11.7690 \\
\hline 27 & B2 А5B5Al & 0.0087 & 0.2088 & 10.1874 \\
\hline 28 & B2A5B & 0.0139 & 0.3336 & 8.4756 \\
\hline 29 & B2 АБB5 A & 0.0580 & 1.3920 & 7.4359 \\
\hline 30 & В2АБВ5А2 & 0.0016 & 0.0384 & 1.6393 \\
\hline 31 & B2A5B & 0.0261 & 0.6264 & 15.3439 \\
\hline 32 & B2 АБB5 & 0.2383 & 5.7192 & 41.9021 \\
\hline 33 & В2АБВ5АЗ & 0.0165 & 0.3950 & 5.6410 \\
\hline 34 & B2 АБВБА: & 0.2215 & 5.3160 & 46.6021 \\
\hline 35 & В2АБВ5АЗ & 0.0045 & 0.1080 & 1.6071 \\
\hline 36 & B2А5B5 & 0.0207 & 0.4968 & 18.4492 \\
\hline 37 & B2 АБB5 & 0.0087 & 0.2088 & 7.2080 \\
\hline 38 & В2АБВ5АЗ & 0.0375 & 0.9000 & | 4.5631 \\
\hline 39 & В2АБВ5А & 0.0434 & 1.0416 & 6.1823 \\
\hline 40 & В2АБВ5АЗ & 0.1265 & 3.0360 & 12.5683 \\
\hline 41 & B2АБB5А & 1.2510 & 30.0240 & 59.8278 \\
\hline 42 & B2 АБВ5АЗЗB 4 & 0.0212 & 0.5088 & 7.2802 \\
\hline 43 & В2АБВ5АЗВ 4 & 0.0679 & 1.6296 & 21.8020 \\
\hline 44 & В2 АБВ5АЗЗ 4 & 0.0436 & 1.0464 & 35.8553 \\
\hline 45 & В2АБВ5АЗЗБ & 0.0221 & 0.5304 & 7.0248 \\
\hline 46 & В2АБВБАЗВВ5 & 0.0288 & 0.6912 & 15.7635 \\
\hline 47 & В2АБВ5АЗВБ5 & 0.0194 & 0.4656 & 20.6823 \\
\hline & Total & 2.6430 & 63.4327 & \\
\hline
\end{tabular}

Tabel 3. Penurunan rugi daya dan rugi energi

$$
\begin{aligned}
\text { Atau sebesar } & =63.4327 / 272.8896 \times 100 \% \\
& =0,232448 \times 100 \% \\
& =23,2448 \%
\end{aligned}
$$

Sehingga penurunan rugi energi rata-rata selama satu bulan menjadi:

$$
\begin{aligned}
\Delta W_{\text {dalam satu bulan }} & =63.4327 \mathrm{Wh} \times 30 \\
& =1,903 \mathrm{kWh}
\end{aligned}
$$

\section{KESIMPULAN}

Berdasarkaan hasil perhitungan yang telah dilakukan, dapat diperoleh kesimpulan sebagai berikut:

1. Penggantian jenis connector di gardu DS.105 dapat menurunkan rugi energi dari 272,8896 Wh sebelum penggatian tap connector menjadi 209,4569 Wh setelah penggantian tap konektor atau sebesar 63,4327 Wh (23,2448\%).

2. Penggantian tap connector ini menyebabkan kualitas tegangan ujung tiaptiap pelanggan menjadi lebih baik, pada 
saat jam beban puncak tidak ada pelanggan yang tegangannya dibawah toleransi minimum (-10\%).

\section{DAFTAR PUSTAKA}

[1] https://www.google.com/\#q=susut+ energi+listrik. Diakses tanggal 07/10/2013.

[2] SPLN 1, Tegangan-Tegangan Standar, 1995

[3] http://www.karya-adikita.com/index.php/produk-kami?start=48/72. Diakses tanggal 07/10/2013

[4] Syahruzadi. D. 2005. Laporan Pengujian CCO Di Badan Penelitian dan Pengembangan PT. PLN (Persero). PT. Karya Adikita Galvanize. Jakarta 